\title{
Acute health effects after accidental exposure to styrene from drinking water in Spain
} \author{
Alberto Arnedo-Pena1, Juan Bellido-Blasco시 , Jose-Luis Villamarin-Vazquez ${ }^{1}$, \\ Jose-Luis Aranda-Mares ${ }^{2}$, Nuria Font-Cardona ${ }^{3}$, Fabriziomaria Gobba ${ }^{1}$ and \\ Manolis Kogevinas*4
}

\begin{abstract}
Address: ${ }^{1}$ Centro de Salud Pública. Dirección Territorial de Salud. Castellón, Spain, ${ }^{2}$ IPROMA. Investigación y proyectos medio ambiente. Castellón, Spain, ${ }^{3}$ Dept. of Hygiene, University of Modena and Reggio Emilia, Modena, Italy and ${ }^{4}$ Environmental and Respiratory Health Research Unit, Municipal Institute of Medical Research, Barcelona, Spain

Email: Alberto Arnedo-Pena - alberto.arnedo@sanidad.m400.gva.es; Juan Bellido-Blasco - juan.bellido@sanidad.m400.gva.es; JoseLuis Villamarin-Vazquez - villamarin_jos@gva.es; Jose-Luis Aranda-Mares - jaranda@iproma.com; Nuria Font-Cardona - jarand@iproma.com; Fabriziomaria Gobba - f.gobba@unimo.it; Manolis Kogevinas* - kogevinas@imim.es

* Corresponding author
\end{abstract}

Published: 22 May 2003

Environmental Health: A Global Access Science Source 2003, 2:6

This article is available from: http://www.ehjournal.net/content/2/1/6

(C) 2003 Arnedo-Pena et al; licensee BioMed Central Ltd. This is an Open Access article: verbatim copying and redistribution of this article are permitted in all media for any purpose, provided this notice is preserved along with the article's original URL.

\begin{abstract}
Objectives: We studied subjective health symptoms in a population accidentally exposed to high styrene concentrations in drinking tap water. The contamination occurred during the reparation of a water tank.
\end{abstract}

Methods: Residents of 27 apartments in two buildings using the contaminated water were contacted. A questionnaire on subjective symptoms was administered to 84 out of 93 persons living in the apartments at the time of the accident. Styrene concentration was measured in samples of water collected two days after the accident. The means of exposure associated with appearance of symptoms were examined through case-control analyses.

Results: Styrene in water reached concentrations up to $900 \mu \mathrm{g} / \mathrm{L}$. Symptoms were reported by 46 persons (attack rate $55 \%$ ). The most frequent symptoms were irritation of the throat $(26 \%)$, nose (19\%), eyes (18\%) and the skin (14\%). General gastrointestinal symptoms were observed with II\% reporting abdominal pain and $7 \%$ diarrhea. The factors most strongly associated with symptoms were drinking tap water $(\mathrm{OR}=7.8,95 \% \mathrm{Cl} 1.3-48)$, exposure to vapors from the basement (OR $=10.4,2.3-47)$ and eating foods prepared with tap water $(O R=8.6,1.9-40)$. All residents in the ground floor reported symptoms.

Conclusions: This accidental contamination led to very high styrene concentrations in water and was related to a high prevalence of subjective symptoms of the eyes, respiratory tract and skin. Similar exposures have been described in workers but not in subjects exposed at their residence. Various gastrointestinal symptoms were also observed in this population probably due to a local irritative effect.

\section{Introduction}

On December 10, 1999, residents of a neighborhood at
Castellón, NE Spain informed the local authorities that drinking tap water had a strong solvent-type smell and 


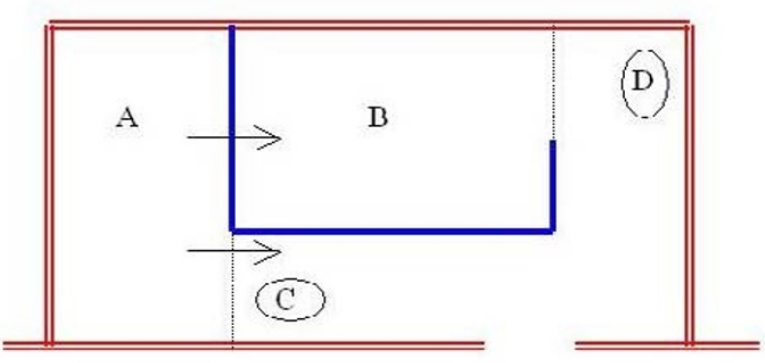

Underground garage

\section{Figure I}

Floor plan of the water tanks in the basement of the building adjacent to the garage. The water tank that was repaired and where a fan was positioned to accelerate the drying the paint is marked as $A$. The drinking water tank that was contaminated with vapors from Tank $A$ is marked as $B$. C indicates the water pump for Tank $A$. $D$ indicates the water pump for Tank $B$. The continuous blue lines indicate the walls separating the tanks that at the time of the accident were not reaching the ceiling. The continuous red lines indicate the walls separating the tanks from the remaining building and from the water tanks. The black dotted lines indicate the windows installed after the accident to facilitate access to the water tanks. The arrows indicate the direction of the vapors from water tank $A$ at the time of the accident.

produced nausea and various other health symptoms when consumed. Drinking water was pumped to the apartments from a tank adjacent to a fire-protection water tank that was repaired and waterproofed some hours earlier (Figure 1). The reparation involved the application of Aropal FS1933, an unsaturated polyester resin based on styrene, and of fiberglass mats. The possibility of a contamination was suggested due to a communication in the air environment of the two tanks. In addition, to facilitate drying, a fan was used which forced vapors from the repaired tank to the drinking water tank. The odor was perceived on the same day of the reparation work, first at the the water tanks, the parking place and later in other parts of the buildings. Residents reported that a thin gelatinous layer could be seen on the water in the tank.

Studies evaluating inhalation exposure have demonstrated that styrene is a strong irritant $[1,2]$. Eye, nose and throat irritation is common at exposure levels above 50 to $100 \mathrm{ppm}$ but can also occur at levels of about 20 to 30 ppm [3]. At very high levels chronic bronchitis type symptoms and other respiratory symptoms appear. Multiple central and peripheral acute nervous system effects have been described at levels of about 100 ppm but some neu-

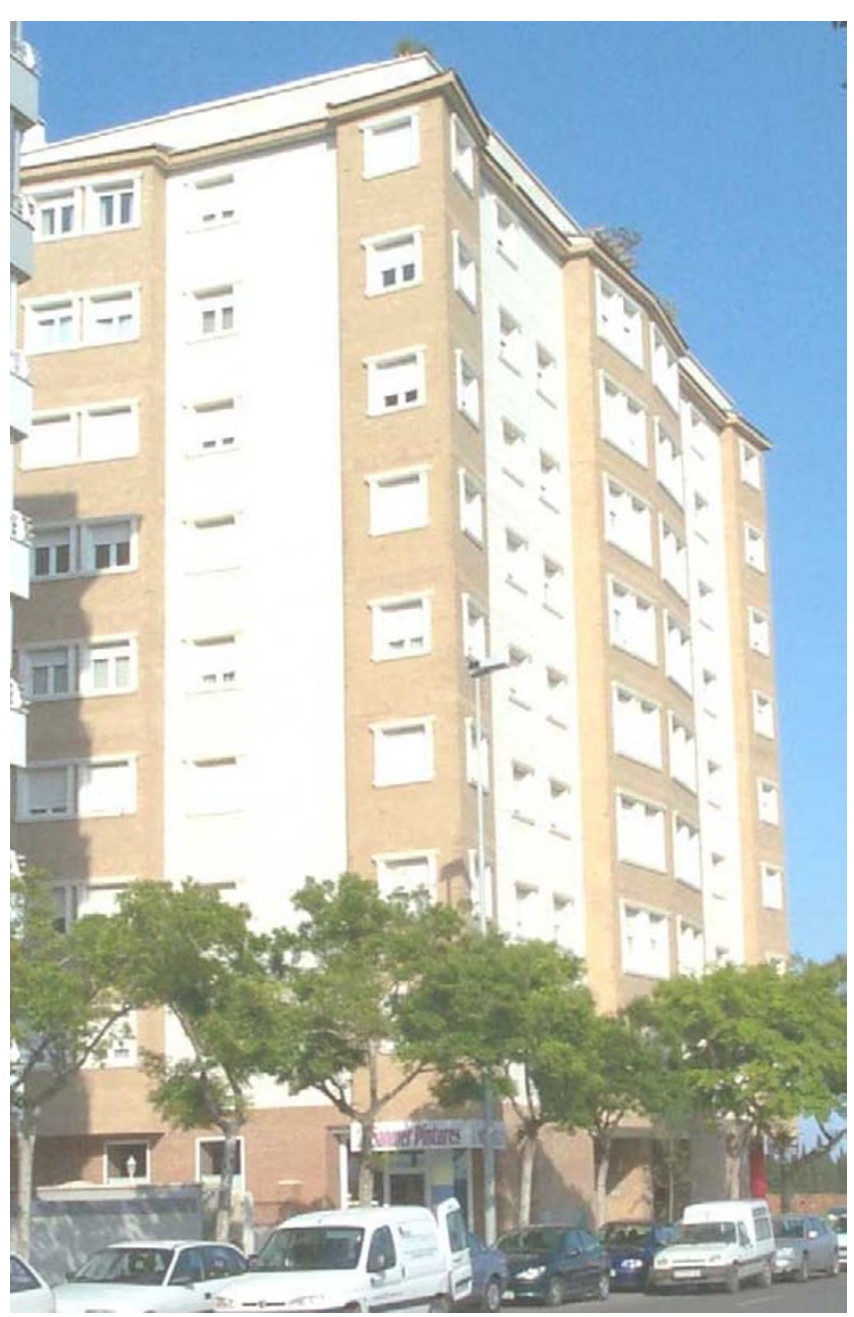

Figure 2

The building where the accident occurred.

rological symptoms and color vision impairment may also appear at much lower levels [4-6]. Effects on the liver (acute in animals, chronic in exposed workers), and the kidney and also genotoxic effects have been described at low levels $[7,8]$. In the past, the so called "styrene sickness" was described in workers heavily exposed to styrene including nausea and vomiting, loss of appetite, and general weakness.

To our knowledge there are no previous reports of an environmental styrene contamination of water leading to health symptoms. In drinking water supplies, styrene is usually either not detected or detected at levels below 1 $\mu \mathrm{g} / \mathrm{L}$ [9]. We present the investigation following this accidental environmental exposure to styrene. 


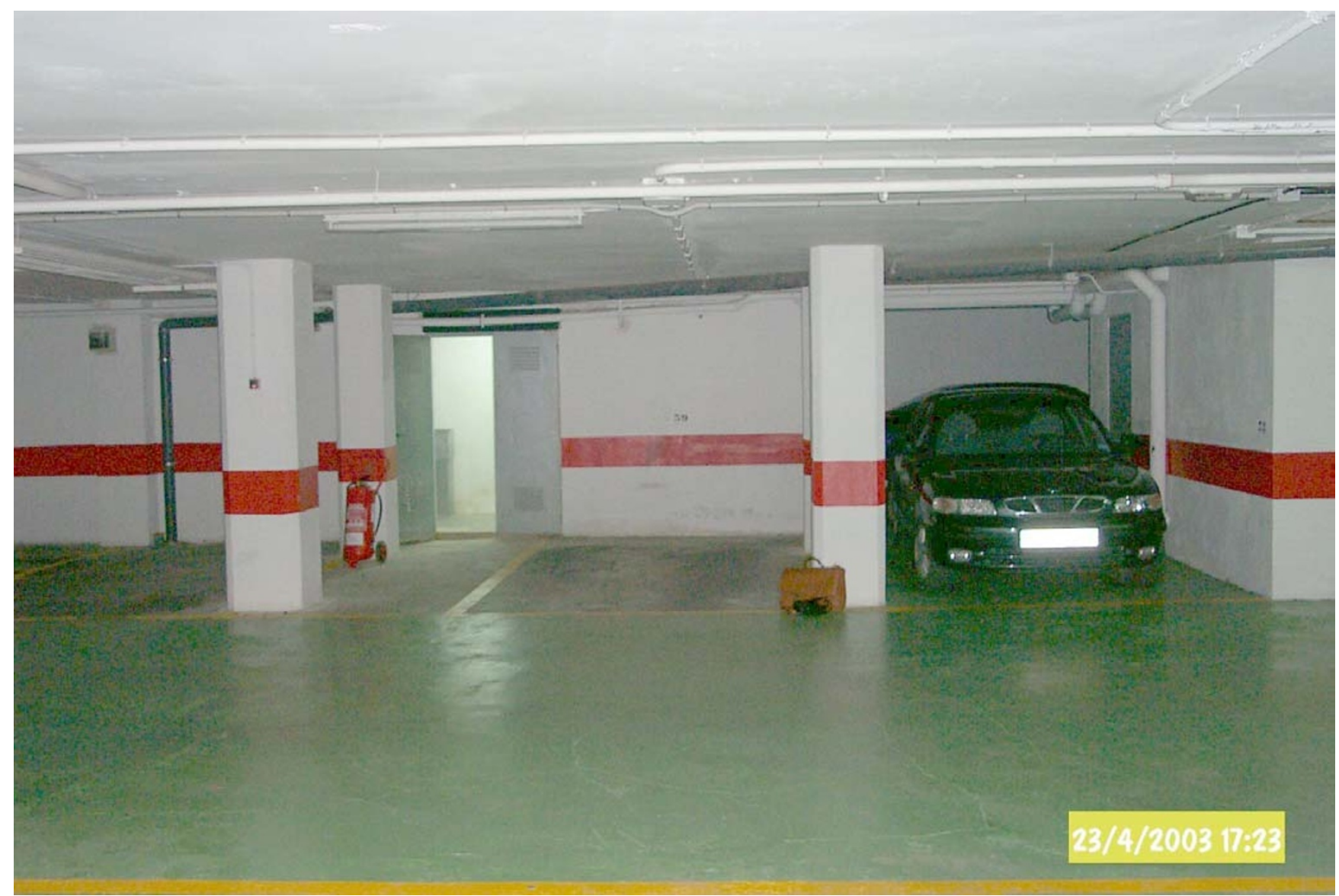

Figure 3

The garage and the door giving access to the water tanks (see Figure I, floor plan)

\section{Methods}

Symptoms were reported among occupants of 30 apartments in two neighboring buildings (Figure 2), all using the same drinking water tank (Figures 3,4,5). A 100\% census sample was defined and contacted and residents of 27 apartments participated in the study. A self-reported questionnaire (Annex 1 - see table 5) was administered requesting information on socio-demographic factors, various subjective symptoms, and also a list of activities potentially related to individual exposure, such as drinking tap water, eating foods prepared with tap water, bathing or showering. Of the 93 persons living at the time of the accident in the apartments, 84 completed the questionnaire on day 4. Parents completed questionnaires for children less than 14 years $(n=26)$. Among subjects 44 were male and 40 were female, and the mean age was 29 years (range 8 months to 77 years).

Among 15 subjects who reported symptoms, a sample of urine was collected on day 5 for analysis of the two main metabolites of styrene, namely mandelic and phenylglyoxylic acids (MA and PGA respectively) and of creatinine. Measurement were performed by gas chromatography at an accredited laboratory in Barcelona

The residents collected tap water samples at the second day after the accident. A more systematic sampling was done after the third day by the local health authority. Samples were analyzed by gas chromatography/mass spectrometry.

The reparation work at the firewater tank involved the application of an unsaturated polyester resin based on styrene (Aropal FS1933), followed by a cap of fiberglass mats (MAT300) containing 35\% fiberglass, and then by a white gel coat based on styrene that contained a low (4-6\%) proportion of a paraffin.

The sources of exposure that were associated with the occurrence of symptoms were examined through case-con- 


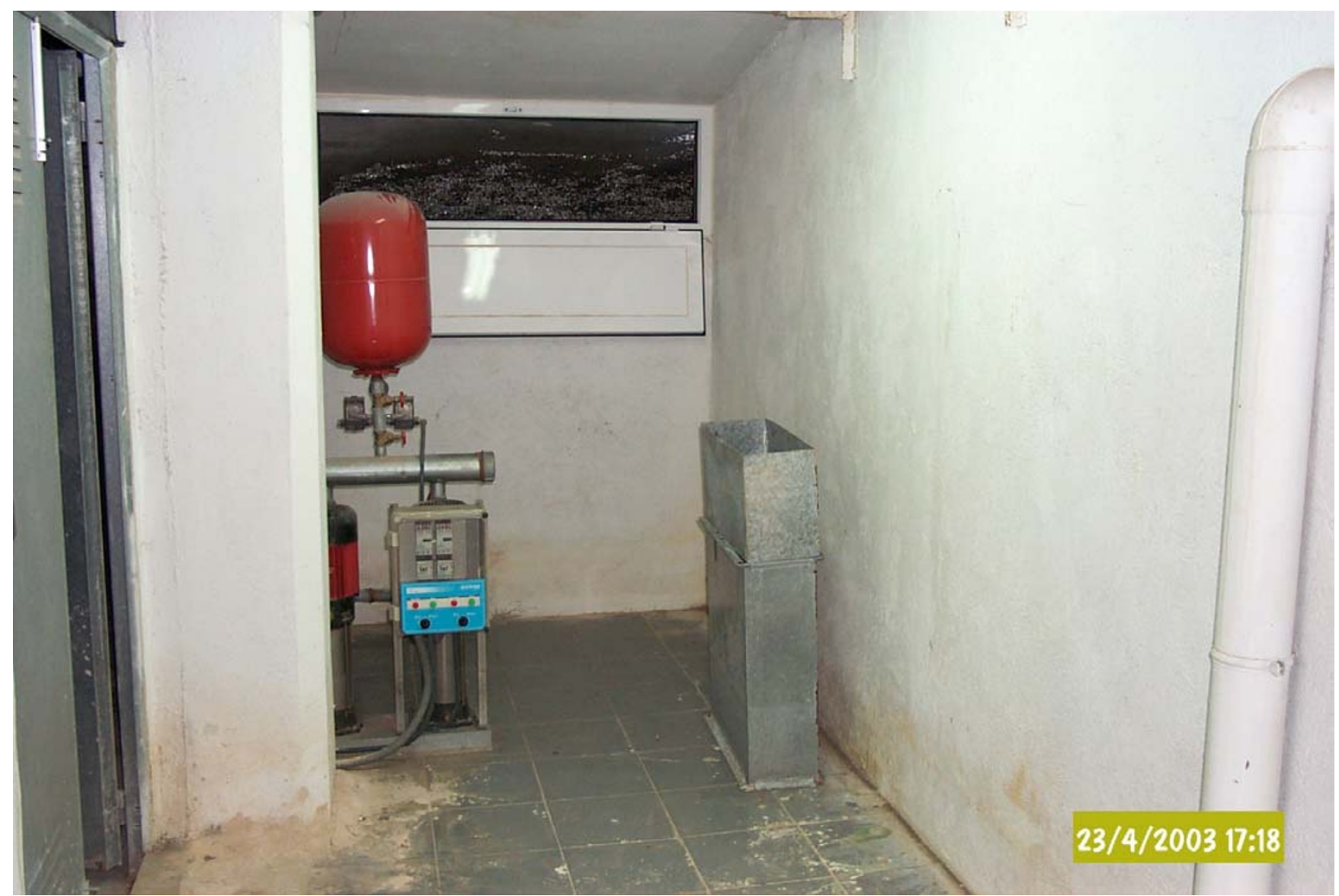

Figure 4

View towards water tank $A$ and water pump for this tank (see Figure I, floor plan). The photo was taken after the water tanks were completely separated.

trol analyses (10). Cases were defined as those subjects having any symptom $(n=46$, mean age 30 years, range 8 months to 77 years), and the remaining subjects were defined as controls $(n=38$, mean age 27 years, range 8 months to 72 years). Unconditional logistic regression was used, adjusting for age, sex, and when appropriate housing characteristics. The STATA 3.1 statistical package was used [11].

\section{Results}

Water samples analyses indicated very high concentrations of styrene in samples collected during the second and the third day after the episode, with measured levels up to $900 \mu \mathrm{g} / \mathrm{L}$ (Table 1). Analyses did not identify contamination of the drinking water by glass fibres that could have been released from the reparation work. Low styrene levels in water were observed after day 4 . Low levels were also found for agents such as toluene, and other dissolved hydrocarbons. MA and PGA were not detected in the urine samples collected at day 5. Results of bacteriological analyses in water were normal.

Symptoms were reported by 46 of the 84 persons interviewed (attack rate $54.8 \%$ ). The onset of symptoms was December 10 (Day 1) for 44 subjects and December 14 (Day 5) for 2 cases. The average duration of symptoms was 2.8 days with a standard deviation of 1.6 days. Physicians attended nine subjects and confirmed irritation type symptoms but none of the subjects were hospitalized. The most serious case was of one resident who developed acute conjunctivitis after opening the door leading to the tank and being exposed to the confined environment. Solvent type odors were perceived by $89 \%$ of the subjects and a bad taste in tap water by $61 \%$. The most frequent symptoms (Table 2), were irritation of the throat (26\%), eyes (18\%) and the skin (14\%). Around $10 \%$ of the subjects reported general gastrointestinal symptoms, particularly abdominal pain. Among the 26 children below 14 years 


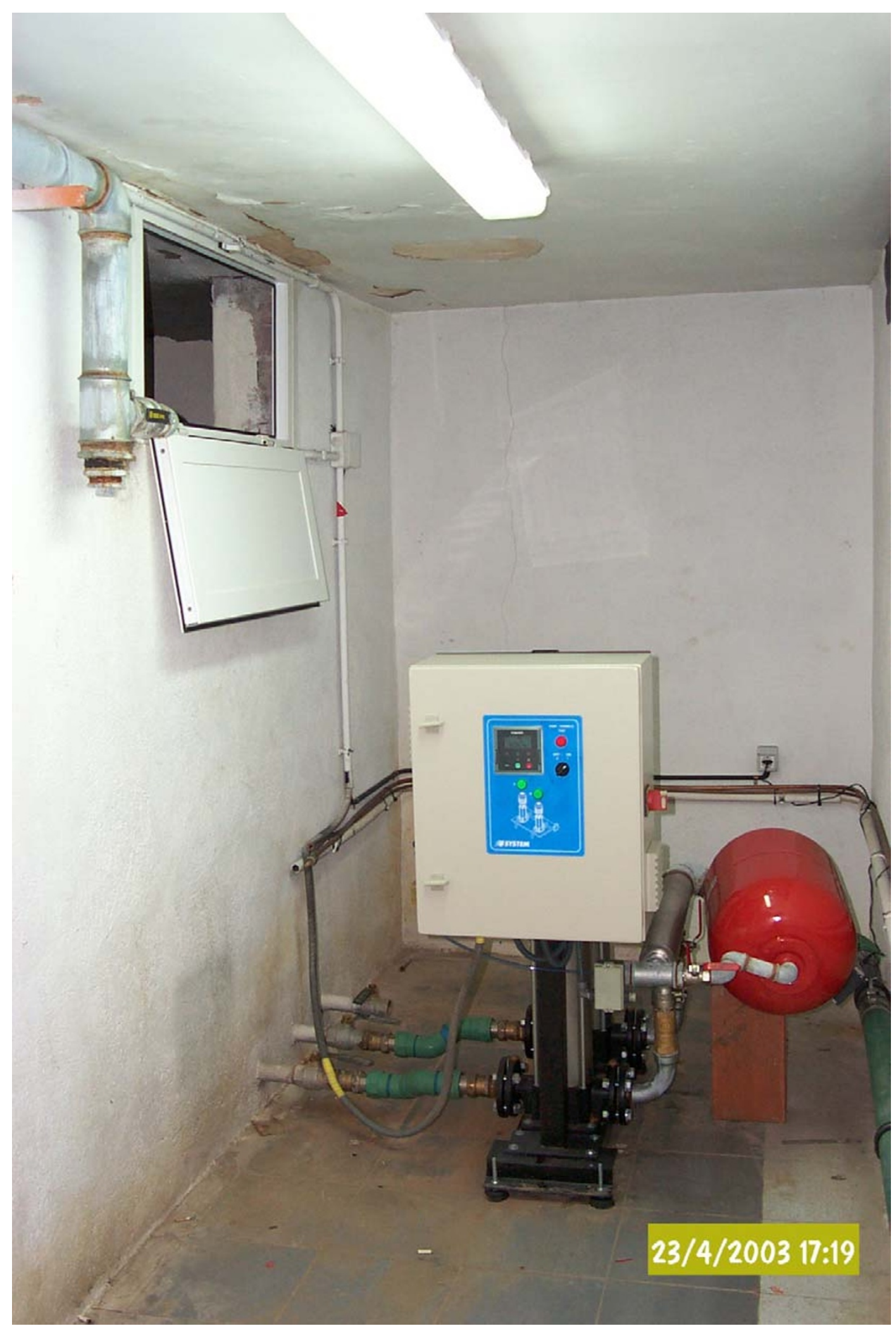

Figure 5

View towards water tank B and water pump for this tank (see Figure I, floor plan). The photo was taken after the water tanks were completely separated. 
Table I: Styrene and toluene concentrations $(\mu \mathrm{g} / \mathrm{L})$ in drinking water samples

\begin{tabular}{|c|c|c|c|}
\hline Place & Day & Compound & Level ( $\mu \mathrm{g} / \mathrm{L})$ \\
\hline \multirow[t]{2}{*}{ Apartment Ist floor } & II Dec & Styrene & 905 \\
\hline & & Toluene & 7.5 \\
\hline \multirow[t]{2}{*}{ Apartment $3^{\text {rd floor }}$} & II Dec & Styrene & 779 \\
\hline & & Toluene & 6.6 \\
\hline \multirow[t]{2}{*}{ Apartment $8^{\text {th }}$ floor } & $12 \mathrm{Dec}$ & Styrene & 767 \\
\hline & & Toluene & 6.8 \\
\hline \multirow[t]{2}{*}{ Apartment $4^{\text {th }}$ floor } & $14 \mathrm{Dec}$ & Styrene & $<0.5$ \\
\hline & & Toluene & $<0.5$ \\
\hline \multirow[t]{2}{*}{ Water tank } & $14 \mathrm{Dec}$ & Styrene & 0.6 \\
\hline & & Toluene & 0.5 \\
\hline \multirow[t]{2}{*}{ Apartment $4 \mathrm{t}$ floor } & $17 \mathrm{Dec}$ & Styrene & $<0.5$ \\
\hline & & Toluene & $<0.5$ \\
\hline
\end{tabular}

Table 2: Prevalence of reported symptoms by the residents of the apartments using styrene contaminated water.

\begin{tabular}{lll}
\hline Symptoms & No. & Relative prevalence \\
\hline Irritation, throat & 22 & $26 \%$ \\
Irritation, nasal & 16 & $19 \%$ \\
Irritation, eye & 15 & $18 \%$ \\
Irritation, skin & 12 & $14 \%$ \\
Nasal secretion & 9 & $11 \%$ \\
Abdominal pain & 9 & $11 \%$ \\
Diarrhea & 6 & $7 \%$ \\
Nausea & 6 & $7 \%$ \\
Skin eruption & 5 & $6 \%$ \\
Fever & 3 & $4 \%$ \\
Vomit & 1 & $1 \%$ \\
Total with symptoms & 46 & $55 \%$ \\
Total study population & 84 & \\
\hline
\end{tabular}

Table 3: Prevalence of any reported symptom by apartment floor

\begin{tabular}{lllll}
\hline & Floor & & & \\
& Ground & Ist & 2 nd & $3-8^{\text {th }}$ \\
Subjects with symptoms & 10 & 5 & 6 & 15 \\
Subjects without symptoms & 0 & 3 & 7 & 28 \\
Prevalence (\%) & $100 \%$ & $63 \%$ & $47 \%$ & $35 \%$ \\
\hline
\end{tabular}

of age, 11 reported symptoms incluing one of two infants. Distance from the source was one of the factors related to symptoms, with all residents in the ground floor reporting symptoms (Table 3), and lower percentages reported in higher floors (chi square for trend 13.43, p < 0.01).
The factors most strongly associated with the occurrence of symptoms were drinking tap water ( $\mathrm{OR}=7.8$ ), exposure to vapors from the basement $(\mathrm{OR}=10.4)$ and eating foods prepared with tap water after the occurrence of the contamination $(\mathrm{OR}=8.6)$. Other factors, such as bathing and showering, length of stay indoor after the contamina- 
Table 4: Exposure after the accident associated with occurrence of symptoms in the case-control analysis

\begin{tabular}{|c|c|c|c|c|}
\hline Factors & Cases $(n=46)$ & Controls $(n=38)$ & Odds ratio* & $95 \%$ confidence interval \\
\hline Age (mean, range) & $29.9,8 m-77 y r$ & $26.8,8 \mathrm{~m}-72 y r$ & 1.0 & $0.97-1.04$ \\
\hline Sex (female/male) & $23 / 23$ & $|7 / 2|$ & 1.3 & $0.4-4.2$ \\
\hline Presence in the house between 10-13 December & 42 & 32 & 1.9 & $0.2-24.3$ \\
\hline Consumption of tap water & 21 & 3 & 7.8 & I.3-48. I \\
\hline Consumption of food prepared with tap water & 34 & 13 & 8.6 & $1.9-39.8$ \\
\hline Shower/bath & 41 & 24 & 1.6 & $0.4-7.7$ \\
\hline Direct exposure to vapors from basement & 34 & 18 & 10.4 & $2.3-47.4$ \\
\hline Floor of the apartment (continuous) & & & 0.7 & $0.5-0.96$ \\
\hline
\end{tabular}

* Odds ratios are adjusted for the other variables shown in the table

Table 5:

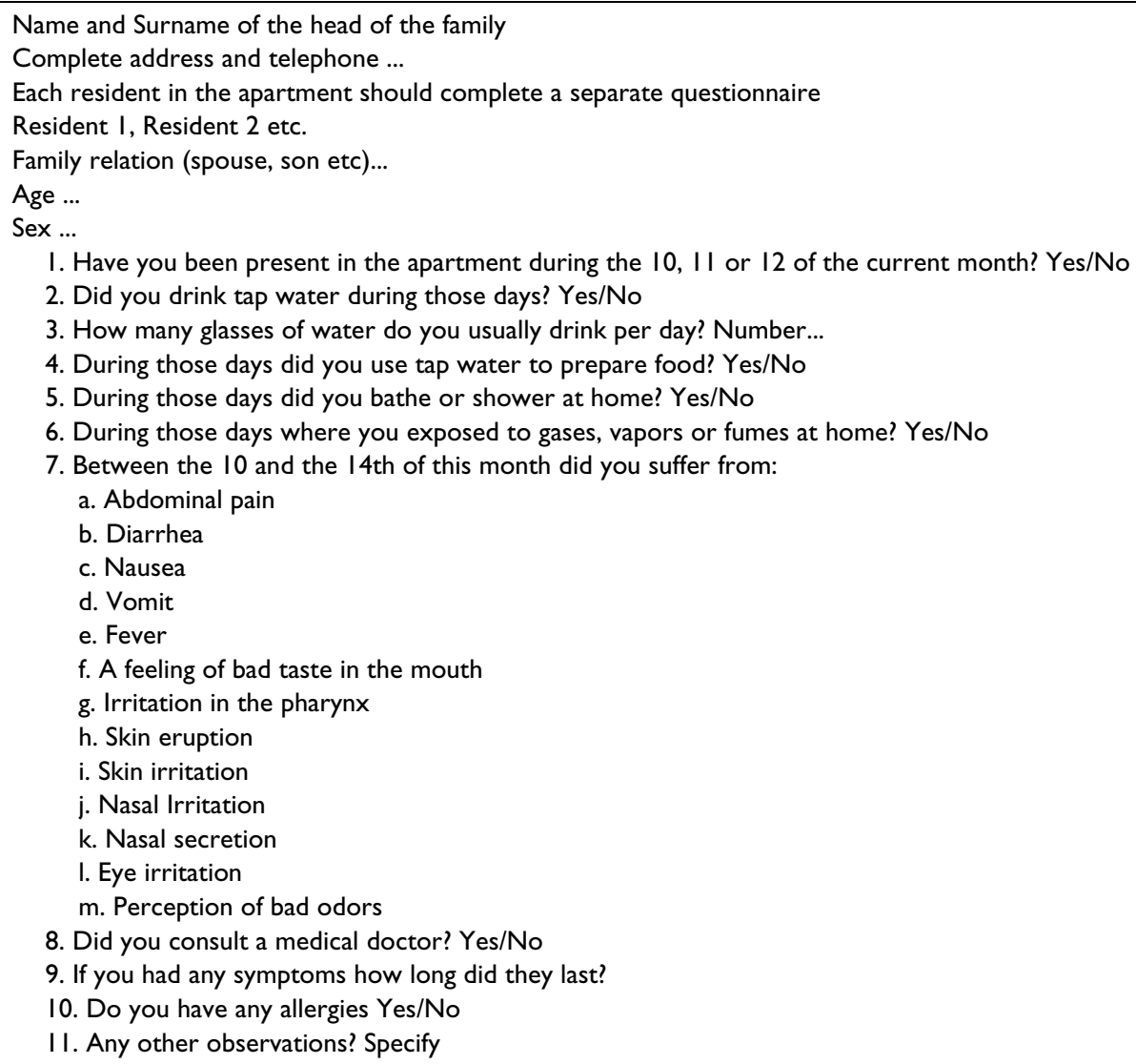

Annex I. Questionnaire to be completed by the residents of the building.

tion, were also associated although results were not statistically significant (Table 4).

Cases consumed a larger quantity of tap water at home $($ mean $=0.72 \mathrm{~L} /$ day) compared to controls (mean $=0.42$ L/day) but differences were not significant. Among the 26 children the two main risk factors were exposure to vapors and eating food prepared with tap water, although differences were not statistically significant.

\section{Discussion}

The accidental contamination of a drinking-water tank in Castellón led to levels of styrene in tap water that were 2 to 3 orders of magnitude higher compared to the levels 
usually measured in drinking water [9]. An increased prevalence of reversible health symptoms was observed in subjects using water from the contaminated tank. The close time relationship between the application of the styrene-based material and the occurrence of symptoms that can be induced by styrene in humans point to styrene as the most likely candidate for the occurrence of symptoms, although the possibility of the presence of other undisclosed contaminants cannot be entirely ruled out. The effects of styrene in humans has been studied in workers exposed to high concentrations of the solvent in air but there are no published data on subjects exposed in their residence as a consequence of water contamination. In addition to the irritative effects to the eye, skin and respiratory tract frequently reported in workers, various gastrointestinal type symptoms were observed in this population that ingested highly contaminated water.

The population involved in the accident was well defined, and the non-participation rate was low and unlikely to have modified the results. No comparison population was used, e.g., residents in neighboring buildings, and the relative increase of the prevalences is unknown. However, the prevalence of most symptoms appears high and very likely above background prevalence. The general household health survey of Spain [12] only includes information for wide categories of symptoms that do not exactly correspond to symptoms reported in this study. Problems in the throat, cough, simple cold or influenza that limited the free time activities during the last two weeks were reported by $2.8 \%$ of adults in Spain, headache by $2 \%$, nausea or vomit by $0.9 \%$ and diarrhea or other intestinal problems by $0.4 \%$ [12].

Styrene is an environmental contaminant, and low doses have been reported in drinking water (usually $0.1-0.2 \mu \mathrm{g} /$ l) and in some foods as beer and coffee (10-350 $\mu \mathrm{g} / \mathrm{kg})$ $[9,13]$. Styrene concentration in water measured in our study was about two to three orders of magnitude higher. The presence of high concentration of the solvent was clearly perceived by subjects. A thin gelatinous layer on the surface of water in the tanks due to the poor water solubility of styrene [14] was visible, and nearly all subjects perceived the odor. The taste threshold concentration in water is around $0.7 \mathrm{mg} / \mathrm{L}[15]$.

Given the very high levels measured in water, it could be expected that extensive exposure of the skin and the mucosa occurred. Levels of individual exposure after the accident are, however, unknown. Mandelic and phenyglyoxylic acids were not detected in the urine samples collected at day 5 . Nevertheless, this is not surprising considering that in humans the kinetics of styrene is fast, with an excretion half-time of both metabolites that is about 5-10 hours $[16,17]$.
The main symptoms described in the population examined are acute irritation to the eyes, nose, throat and skin. These effects are probably not related to systemic absorption, but mainly due to local contact. Usually, exposure to styrene is by inhalation and there are several studies on the kinetics of this solvent following inhalation exposure [17] while gastrointestinal tract exposure has not been studied in humans. Studies in animals (mainly rat and mouse) suggest that styrene is absorbed and rapidly metabolised following oral administration [1]. The presence of symptoms of the gastrointestinal tract, such as abdominal pain and diarrhea is not among complaints usually referred by workers, even if nausea is among symptoms included in the so-called "styrene sickness" [18]. Possibly, gastrointestinal symptoms should be considered related to the local irritant action of styrene in ingested water or foods. This is also suggested by the relation observed between symptoms and consumption of water and of food prepared with water.

The prevention measures applied should be aimed at avoiding further contact with styrene-contaminated drinking water until concentrations reached low levels. Exposure to styrene was high but was limited in time and it seems unlikely that long-term effects will occur following this accidental exposure. This accident was caused by a series of failures at various levels of control and the prevention of similar accidents requires a conjunct of measures. In the case of this residential building in a Spanish city, the drinking water tank was not isolated from the fire protection water tank, nor was it isolated from car emissions from the parking garage in the basement, nor completely isolated from possible animal contact. In the first place, the architects and constructor should not have designed and built the two communicating water tanks without adequate ventilation. Subsequently the municipality should have done a complete inspection for the building before permitting its reoccupancy. The company doing the repair was unaware of potential toxic effects of the chemicals applied, and measures should be taken to inform companies and workers on the potential toxicity of the materials used. Furthermore the type of products applied in construction and repair of drinking water tanks should be regulated and clearly labeled. Several state agencies regulate the procedures for the use of environmental contaminants and potentially toxic agents and should collaborate to inform about these risks and apply regulations. This accident highlights the precarious conditions for water safety administration in some residential areas in Spain.

\section{Competing interests}

None declared 


\section{Authors' contributions}

AAP, JBB and JLVV carried out the field study, did the statistical analysis and participated in the manuscript preparation. JLAM and NFC did the laboratory analyses. FG and MK drafted the manuscript. All authors read and approved the final manuscript.

\section{References}

I. Bond J Review of the toxicology of styrene Crit Rev Toxicol I989, 1 9:227-49

2. Proctor $\mathrm{NH}$, Hughes JP and Fischman ML Chemical hazards of the workplace Philadelphia: JB Lippincott Company 1988, 448-49

3. Rabovsky J, Fowles J, Hill MD and Lewis DC A health risk benchmark for the neurologic effects of styrene: comparison with NOAEL/LOAEL approach Risk Anal 200I, 21:1 17-26

4. Gobba F, Cavalleri F, Bontadi D, Torri P and Dainese R Peripheral neuropathy in styrene-exposed workers Scand J Work Environ Health 1995, $21: 517-20$

5. Edling $C$, Anundi $H$, Johanson $G$ and Nilsson $K$ Increase in neuropsychiatric symptoms after occupational exposure to low levels of styrene $\mathrm{Br} J$ Ind Med 1993, 50:843-50

6. Castillo L, Baldwin M, Sassine MP and Mergler D Cumulative exposure to styrene and visual functions Am J Ind Med 200 I, 39:35I60

7. Brodkin CA, Moon JD, Camp J, Echeverria D, Redlich CA, Willson RA and Checkoway $\mathrm{H}$ Serum hepatic biochemical activity in two populations of workers exposed to styrene Occup Environ Med 200I, 58:95-102

8. IARC working group on the evaluation of carcinogenic risks to humans some industrial chemicals IARC Monogr Eval Carcinog Risks Hum 1994, 60: I-560

9. Newhook R and Caldwell I Exposure to styrene in the general Canadian population IARC Sci Publ 1993, 127:27-33

10. Pearce $N$ The four basic epidemiologic study types J Epidemiol Biostat 1998, 3:17I-77

II. Stata Reference Manual Release 3.I College Station, Texas, USA: Stata Corporation 1993,

12. Encuesta Nacional de Salud de España 1997 Ministerio de Sanidad y Consumo, Madrid I999,

13. Miller RR, Newhook R and Poole A Styrene production, use and human exposure Crit Rev Toxicol 1994, 24(Suppl):SI-10

14. Kirk-Othmer Encyclopedia of chemical technology New-York, Intersciences Publ 1969, 19:55-85

15. Baker RA Threshold odors of organic chemicals J Am Water Works Assoc 1963, 55:913-916

16. Galassi C, Kogevinas M, Ferro $G$ and Biocca M Biological monitoring of styrene in the reinforced plastics industry in Emilia Romagna, Italy Int Arch Occup Environ Health 1993, 65:89-95

17. Biological monitoring of Chemical Exposure in the Workplace WHO Guidelines 1996, I:195-204

18. [http://www.inchem.org/documents/pims/chemical/pim509.htm]
Publish with Biomed Central and every scientist can read your work free of charge

"BioMed Central will be the most significant development for disseminating the results of biomedical research in our lifetime. "

Sir Paul Nurse, Cancer Research UK

Your research papers will be:

- available free of charge to the entire biomedical community

- peer reviewed and published immediately upon acceptance

- cited in PubMed and archived on PubMed Central

- yours - you keep the copyright

Submit your manuscript here:

http://www.biomedcentral.com/info/publishing_adv.asp
BioMedcentral 